\title{
Música e Trabalho nas Cidades: o circuito superior marginal e inferior em São Paulo, Rio de Janeiro, Porto Alegre, Goiânia e Recife
}

\author{
Villy Creuz
}

Programa de Pós-graduação em Geografia Humana, Universidade de São Paulo.e-mail: villy.creuz@gmail.com

Recebido em 04/2012. Aceito para publicação em 12/2012.

Versão online publicada em 01/02/2013 (http://seer.ufrgs.br/paraonde)

\begin{abstract}
Resumo - A partir da década de 1990 o conjunto de empresas ligadas à produção, distribuição e consumo de músicas são reorganizadas, em razão da instalação de novos fixos geográficos no território nacional. A disposição de um novo sistema técnico transforma os fatores de produção e a divisão social e territorial do trabalho entre esses agentes. Concomitante a chegada dessas novas famílias de técnicas, há, de igual maneira, a banalização de equipamentos de trabalho, sobretudo aqueles que correspondem à informática e aos insumos à digitalização musical. A informatização do país, em marcha mais acelerada nesses últimos dois decênios, ampliou a espessura da divisão de tarefas entres os atores sociais a trabalhar com a música, em especial, com o alargamento da participação do circuito superior e do circuito inferior. Por meio de algumas situações concretas nos trabalhos de campo em cidades como São Paulo (SP), Rio de Janeiro (RJ), Goiânia (GO), Porto Alegre (RS) e Recife (PE), buscar-se-á demonstrar a coexistência entre esses atores sociais, com atenção focada aos estúdios de gravação e ensaio musical e micro e pequenas gravadoras.

Palavras-chave: Cidades. Técnica e Produção Musical.
\end{abstract}

\section{Novos fluxos: a participação da música no território usado}

0 território usado (Santos, 1996) é o espaço de todos os atores e de todas as instituições, seja qual for sua força e poder. A música é parte da relação biunívoca entre cultura e território, imbuído por certo estágio das técnicas e seus respectivos objetos.

Em 1976, o geógrafo Pierre George (p. 48) afirmava ser "provável que o período atual venha a ser caracterizado, sobretudo, por uma mutação essencial nas relações respectivas entre o homem e a máquina". A produção, distribuição e consumo de músicas perfilha o caráter técnico contemporâneo, no qual o movimento do espaço geográfico pela banalização técnica (Santos, 1994) transforma a estrutura organizacional dos atores sociais.

A experiência do sentir é redimensionada pelo uso dos objetos ao ampliar faculdades humanas ou limitá-las. Para Maurice Merleau-Ponty (1975 ${ }^{1}$, p. 282) "Toda técnica é 'técnica do corpo'. Ela configura e amplia a estrutura metafísica da nossa carne". Nesse sentido, a produção e o consumo musical suscitam essa esfera do sentir e do pensar nos indivíduos. Estruturas do sentir e do pensar são ampliadas e banalizadas, por meio dos fixos geográficos instalados no território, dilatando por meio de suas funções a capacidade de comunicação entre os homens.

A música (uma técnica sonora em si mesma) incorpora à sua produção novos objetos técnicos concretos (Simondon, 2007), reformulando a relação dos atores consigo mesmos e com o entorno. De acordo com Daniel Barenboim (2009, p. 125), "O poder da música reside em sua capacidade de se comunicar com todos os aspectos do ser humano".

A música possui o poder de incitar a alegria ou a introspecção, a melancolia ou o riso, a passividade ou o protesto; e, certamente, os intermezzos desses extremos.

Michel Maffesoli (2009, p. 15), ao ponderar sobre gerações de jovens embalados pelo som de músicas tribais, ressalta o caráter do sentido sonoro na alienação: "Dionísios pós-modernos! Rapazese moças em transe dançam ao som de ritmos bárbaros. A música tecno domina. Pouco importa o resto"; e, assim, o sentido de alheamento é alcançado através de melodias que afloram do mito da puer aeternus (eterna criança).

No livro, A Era do Vazio, Gilles Lipovestky 
(2005, pp. 6-7), a o tratar sobre o valor dado à música, no período histórico atual, escreve:

\begin{abstract}
Vivemos uma formidável explosão musical: música interminável, paradas de sucesso, a sedução pós-moderna é hi-fi. Daqui por diante o aparelho de som é um bem de primeira necessidade, praticamos esporte, passeamos, trabalhamos com música, dirigimos em estéreo, a música e o ritmo se tornaram em poucos decênios parte permanente do nosso ambiente, trata-se de um entusiasmo de massa.
\end{abstract}

Esse movimento do caráter atual da sociedade de consumo musical implica uma fabulosa multiplicação de demandas, culminando em novos postos de trabalho e funções. A técnica se configura enquanto epicentro das divisões do trabalho nas cidades, alterando o caráter da economia urbana, na relação dos objetos com o meio, tornando-se o próprio meio a partir do movimento da sociedade.

A música, como já dissemos, é uma técnica em si mesma que não está dissociada do fenômeno técnico (Santos, 1996). O período atual insere a música (enquanto atividade produtiva) noutro patamar da organização econômica espacial. A técnica de produzir é transformada com os novos equipamentos.

Esses objetos adaptam-se a uma forma de como trabalhar a música. Em outros termos, a forma de lidar com a ferramenta é o próprio entendimento do produto final a ser produzido. A ferramenta produz, antes, o próprio projeto intelectual.

Theodor Adorno (2009, p. 61) considera a técnica um elemento constitutivo do savoir-faire musical.

O lugar dessa lógica é a técnica; para aquele que também pensa com o ouvido, os elementos individuais da escuta se tornam imediatamente atuantes como elementos técnicos, sendo que nas categorias técnicas se revela, essencialmente, a interconexão de sentido.

Essa vivência contemporânea, na qual o agir não está descolado da musicalidade é analisada por G. Lipovetsky (2005, p. 6), consonante as ideias de Maffesoli (2009). Ambos os autores entendem essa situação enquanto fuga em direção a uma ambiência sincopada.

Em outros termos, que nos parece também correto: a produção da individualização do meio é galgada por meio de certa maneira de consumir música.

Essa tendência está em relação com o estado da ordem do mundo. Lipovetsky (2005, p. 7) aponta que a música se encaixa como um eficiente dispositivo adaptado ao "novo perfil do indivíduo personalizado e narcisístico, que tem sede de imersão instantânea".

Nesse sentido, Michel Bull (2000) trata sobre o uso de tocadores musicais, como os anteriores walkmans e, mais recente, os iPods. Essa imersão profunda em novas percepções sensoriais convida a uma maneira de dispor das coisas no território. Transforma a percepção dos conteúdos geográficos e da materialidade concreta dos agentes e das formas de agir, a partir da postura individualizada igualmente cristalizada no consumo musical.

Remetendo-nos, novamente, às indagações de Adorno (2009, p. 241), a música e todas as manifestações de vida musical, não estão desunidas do mundo; ou seja, mesmo as produções que se julgam livres, permanecem ligadas ao mercado capitalista, bem como à vida social que a sustenta.

A música, a musicalidade, a harmonia de sons que resultam em sentidos intencionalizados são veículos que transportam uma larga variedade de conteúdos. A música transmite valores e desenvolve a ligação entre o universo do sentir e do pensar, como fio condutor, levando do éthos ${ }^{2}$ ao pathos $^{3}$. Em outros termos, o próprio território em sua materialidade, em seu conjunto de objetos, relaciona-se com o conjunto de ações, em uma mediação recíproca e contínua, em que a música é um dos elementos do sistema de ações a agir sobre o éthos e sobre o páthos.

Tal perspectiva de estruturação da lógica autoriza elaborar um discurso no qual a ação não esteja focada em determinismos, como uma relação mecanicista: de um lado os dominadores emissores da informação e, de outro lado, os receptores

\footnotetext{
${ }^{2} \mathrm{O}$ termo grego Éthos refere-se ao conjunto dos costumes e hábitos fundamentais, no âmbito do comportamento (instituições, afazeres etc.) e da cultura (valores, ideias ou crenças), característicos de uma determinada coletividade, época ou região; reunião de traços psicossociais que definem a identidade de uma determinada cultura; personalidade de base. Parte da retórica clássica voltada para o estudo dos costumes sociais e/ou conjunto de valores que permeiam e influenciam uma determinada manifestação (obra, teoria, escola etc.) artística, científica ou filosófica. ${ }^{3}$ Páthos trata da qualidade no escrever, no falar, no musicar ou na representação artística (e, p.ext., em fatos, circunstâncias, pessoas) que estimula o sentimento de piedade ou a tristeza; poder de tocar o sentimento da melancolia ou o da ternura; caráter ou influência tocante ou patética.
} 
dominados. A lógica permite antever uma série de processos intermediários, em que resistências e passividades são concomitantes no conjunto de atores do espaço geográfico.

A cultura e a política são pares históricos, bem como a cultura e a técnica e, outrossim, a técnica e a política. Não há separação, ao contrário, o que há são hibridismos, fazendo referência ao que propõe Bruno Latour (2009, p. 9): “Nós mesmos somos híbridos". A recepção de estímulos produzem outros estímulos, de sorte que resistências e passividades acontecem simultaneamente.

0 músico brasileiro, Caetano Veloso, em entrevista a Augusto de Campos (2008, p. 201), quando se refere às novas técnicas de gravação e reprodução da música, então nos anos 1970, observava o movimento contraditório que esses vetores traziam consigo: "de um lado, a Música, violentada por um processo novo de comunicação, faz-se nova e forte, mas escrava; de outro, a Música, resguarda. (...) porque os novos meios de comunicação continuam a funcionar como freio e como novo".

Lucien Goldmann (1972, p. 21), em A Criação Cultural da Sociedade Moderna, indagava:

A comunidade, os valores positivos, a esperança de ultrapassagem, todas as estruturas qualitativas tendem a desaparecer da consciência dos homens para dar lugar à compreensão e ao quantitativo. A realidade perde toda a transparência e se torna opaca; o homem se torna limitado e desorientado; o considerável progresso das forças produtivas e, com elas, da ciência e da técnica, somente se realiza ao preço de um enorme encolhimento do campo da consciência, sobretudo no que respeita às possibilidades do homem e à natureza de suas relações com seus semelhantes.

A técnica, nessa lógica, opera enquanto vetor de encolhimento das capacidades cognitivas do homem de se comunicar (pôr em comum) com seus iguais. Lewis Mumford (1952, p. 15) nos advertia do risco que a técnica impunha ao homem com os automatismos dos processos vitais de produção de arte e dos símbolos: "a máquina automática tende a substituir a pessoa e tomar decisões por ela-ao mesmo tempo que, pelo seu trabalho uniforme, exerce uma verdadeira paralisia sobre toda aquela parte da personalidade que não se conforma facilmente com suas necessidades mecânicas". E assim, nesse mecanismo, a produção musical, em suas diferentes etapas de produção, entra em contato crescente, com os automatismos digitais, que figura em um modelo de consumo face ao modo de produção. Caímos, portanto, no risco de perder o atributo de certa qualidade humana em favor dos instrumentos e/ou dos equipamentos de trabalho.

No entanto, retomamos a ideia de que a música é em si uma técnica. São conjuntos de notas tocadas em harmonia, cujo resultado é a intenção mais ou menos melhor articulada na transmissão de sentidos. 0 problema não é a técnica, da qual a própria atividade musical não poderia prescindir, mas o uso tecnológico que arrebataria a emotividade que a extrema racionalização técnica pode reger.

A música perpetra possibilidades múltiplas: novos campos de ação, enquanto potência, mais suas restrições: ambos os movimentos em consonância. Como ponderava Bruno Latour (2009, p. 10), "A cada vez, tanto o contexto quanto a pessoa humana encontram-se redefinidos". Diríamos, acrescendo a observação do autor, os contextos e as pessoas são definidos pelo estágio das técnicas.

\section{Situações Concretas da economia urbana}

Observamos diferentes situações geográficas (Silveira, 1999) a partir dos trabalhos de campo em São Paulo, Rio de Janeiro, Porto Alegre, Goiânia e Recife. Em cada uma dessas cidades encontramos especificidades, tipos e regularidades de consumos musicais distintos.

O intuito é evidenciar novas características da economia urbana. Faremos isso com as empresas ligadas à música no circuito superior marginal (emergente e residual) e no circuito inferior da economia.

Aqui, apenas à guisa de introdução ao tema dos circuitos da economia urbana: estes são definidos pela coexistência nas cidades de diferentes capacidades de consumo. A desigualdade é a produtora desses dois subsistemas urbanos. Milton Santos (2004, p. p. 277) escreve que "A organização do espaço pelos dois circuitos compreende: 1) as atividades capazes de uma macroorganização do espaço; 2) as atividades incapazes de macroorganização do espaço". Essas distintas capacidades de força e influência, capacidade de ação e consumo, e também de força política, estão em relação com a polarização entre indivíduos e firmas dos dois subsistemas urbanos: o circuito superior e inferior.

A forma pela qual o espaço geográfico é organizado nas cidades resulta na manutenção dos dois subsistemas do sistema urbano. Dentro desse sistema, três variáveis são centrais: técnica, organização e volume de capital.

A técnica banalizada evidentemente orga- 
niza de outra maneira a economia entre as firmas de micro e pequeno porte, conferindo aos atores não-hegemônicos renovadas qualidades do trabalho e a possibilidade de gerar riquezas, como veremos adiante.

É para o que chama nossa atenção María Laura Silveira (2009, p. 20) quando trata do uso dessas tecnologias:

tanto pela expansão dos novos produtos, amiúde tornados instrumentos de trabalho em atividades não-hegemônicas, como pela proliferação de atividades de conserto que permitem a reutilização dos bens, ou mesmo pela distribuição tantas vezes desinteressante para os grandes capitais, os circuitos superior marginal e inferior participam, de forma crescente e por vezes contraditória, na produção da unicidade técnica.

É nessa perspectiva que a banalização técnica ganha força no território usado, expandindo as possibilidades de ação dos atores e não apenas do circuito superior. Observaremos a seguir algumas situações.

\subsection{A Produção musical entre empresas do circuito superior marginal}

A produção musical é realizada, também, por micro, pequenas e médias empresas do circuito superior marginal. 0 barateamento dos equipamentos de trabalho (mesas de som, computadores, programas e softwares, microfones e cabos) e a digitalização da produção musical (com a substituição das gravações analógicas) permitiu o aumento da divisão social e territorial do trabalho nas cidades, englobando um conjunto dessas atividades.

Trataremos de situações analisadas em empresas como estúdios de gravação e ensaio musical, gravadoras e comércios - em que foram realizadas entrevistas abertas com músicos e donos de estabelecimentos, como as lojas de instrumentos musicais e lojas ou ambulantes a comercializar discos.

Em diferentes cidades brasileiras, nas distintas grandes regiões, há um modo de produzir música comum a todos os atores do circuito superior marginal. Os equipamentos de trabalho podem mudar numa variação de marca e modelo, pode haver um conjunto maior ou menor de funções, maior ou menor número de canais, melhor amplitude na receptividade do som, entre outros, isso porque dentro do mesmo sistema de técnicas existem graus de sofisticação e de preços. Todavia, o sistema de objetos conduz ao mesmo conjunto de ações nos diferentes lugares.

As situações analisadas denotam esse processo urbano, em diferentes lugares, com lógicas comuns. As formas de agir são impregnadas por um mesmo sistema de objetos, de modo que a tecnoesfera se cristaliza em todo território nacional. Os sistemas técnicos não são mais locais; "o subsistema técnico hegemônico tornou-se ubíquo" (Santos, 1996, p. 153).

Esse novo sistema técnico universal, onipresente em todos os lugares e que se comunica com todas as técnicas do planeta, edifica o projeto da universalidade técnica, configurando a chamada "unicidade técnica" (Santos, 1996, pp. 151-156).

É por meio da unicidade técnica que a música passa a ser produzida diante de um modo de se fazer único, tornado banal e acessível, porém prescrevendo fórmulas a seguir e objetos a utilizar. Os equipamentos são supervalorizados nas empresas de gravação, já que conferem graus de valorização do serviço prestado.

A instrumentalização ganhou novos conteúdos: os programas para operacionalizar as gravações digitais, hoje, são imperiosos no cotidiano dessa presteza. Entre esses estão o Sound Ford, Pro tools, Sonar, Midi, Reason, Kake Walk e Nero que permitem o ajuste digital das gravações, como volume, equalização, afinação de voz e, do mesmo modo, autorizam a execução dessas em meio virtual.

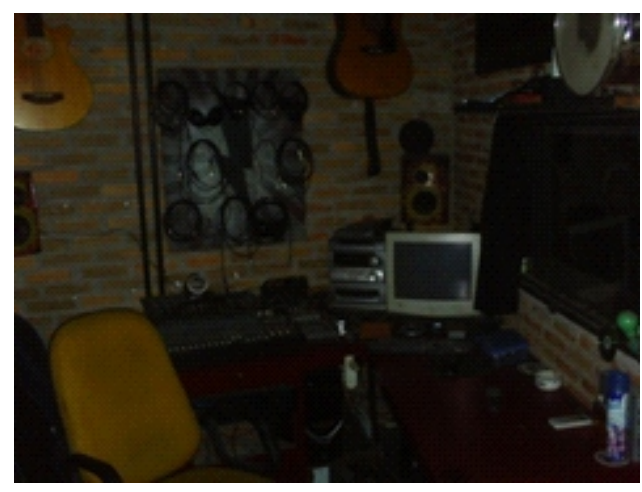

Figura 1. Equipamentos de Trabalho em Estúdio, Porto Alegre - RS, agosto de 2010. Autor: Villy Creuz

O uso da Internet não se revela imperativo para os estúdios visitados em São Paulo, Rio de Janeiro, Porto Alegre, Recife e Goiânia, uma vez que a maioria dos computadores executam, exclusivamente, tarefas em programas específicos de gravação. Muito embora os equipamentos não tenham Internet, outros computadores são utilizados para atender a essa demanda. A maior parcela dos entrevistados garantiu usar a Internet apenas em 
suas residências e não a relacionam com a propaganda de suas firmas.

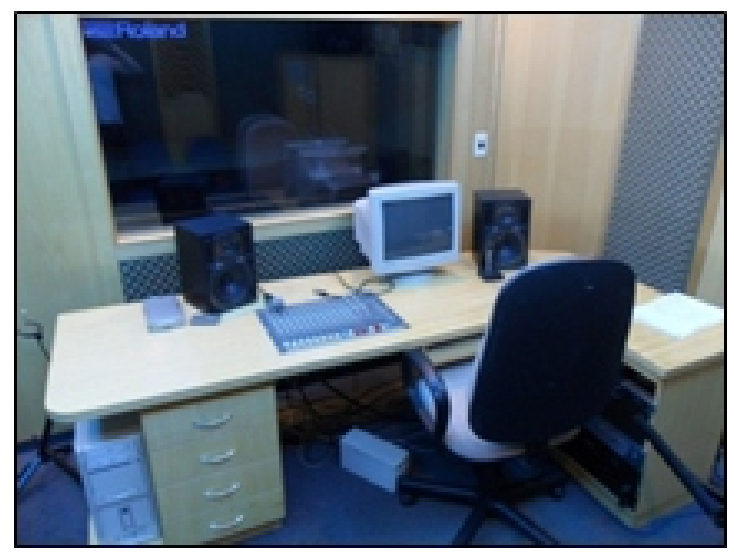

Figura 2. Gravadora Evangélica- sala de gravação, Goiânia - GO, novembro de 2010. Autor: Villy Creuz

Com o uso da informática, microcomputadores, mesas de som e programas específicos nas gravações, cria-se a nova especificidade quanto ao tipo de serviço que os estúdios oferecem, além da gravação, mixagem, masterização, agora, novas possibilidades: a reprodução de discos (algumas vezes piratas), produção de jingles e spots para agências de propaganda e, também, trilhas para filmes, exposições artísticas e teatros.



Figura 3. Sala de Gravação, estúdio de gravação e ensaio musical, São Paulo, outubro de 2011. Autor: Villy Creuz

Há uma demanda constante de renovação de equipamentos ligados à qualidade sonora, qualidade digital, qualidade acústica, transmissão na gravação, enfim, toda uma série de elementos que contribuem para a renovação inexaurível dessas técnicas. Gera-se o consumo permanente e o reinvestimento em capital fixo nessas empresas, utilizando-se ou de capital próprio ou de empréstimos pessoais em bancos, como pessoa física.

Todos os equipamentos, em conjunto, se organizam em pequenos sistemas técnicos. A mesa de som depende, por sua vez, das caixas de retorno, que necessitam, também, dos cabos específicos para a transmissão da informação, mais o conjunto de telas e os computadores que coordenam todas as variáveis acústicas, através de seus softwares. São técnicas solidárias entre si e interdependentes. Seu conjunto pressupõe uma unidade que, uma vez desfeita, paralisa todo o sistema. Esse mutualismo técnico nunca foi tão agudo.



Figura 4. Mesa de som e equipamentos, Rio de JaneiroRJ, maio de 2011. Autor: Villy Creuz

O insumo utilizado pelos estúdios de gravação é o CD virgem. Esse material é, normalmente, comprado nas centralidades ou por telefone e entregue no próprio estúdio, ou ainda, em centros comerciais dos bairros onde as compras são realizadas em pequenos lotes. Os estúdios não criam estoques, pois os entrevistados asseguram que o CD virgem é muito fácil de ser encontrado. A aquisição do material é levada em consideração junto à demanda existente, ou seja, se muitas gravações são previstas é efetuada uma compra anterior à data estipulada da prestação do serviço de gravação.

A possibilidade de gravar em discos virgens e transportar a música e repassá-la a outros agentes redimensiona o caráter da produção nacional e a distribuição de mercadorias musicais.

Vimos situações concretas em que estúdios, diversificando suas atividades, passaram a reproduzir discos em até 700 unidades. Verificaram-se dois casos em Recife; três em Goiânia; quatro em São Paulo; três no Rio de Janeiro; e, um em Porto Alegre. Os equipamentos de trabalho são os mesmos e a produção implica o empenho manual humano, unidade por unidade.

É comum os estúdios de gravação musical adquirirem equipamentos usados, como mesas de som, amplificadores, microfones de diversos mode- 
los, caixas de som, para diversos fins e instrumentos musicais - bateria, piano, violão, guitarra - cordas e metais, no geral.

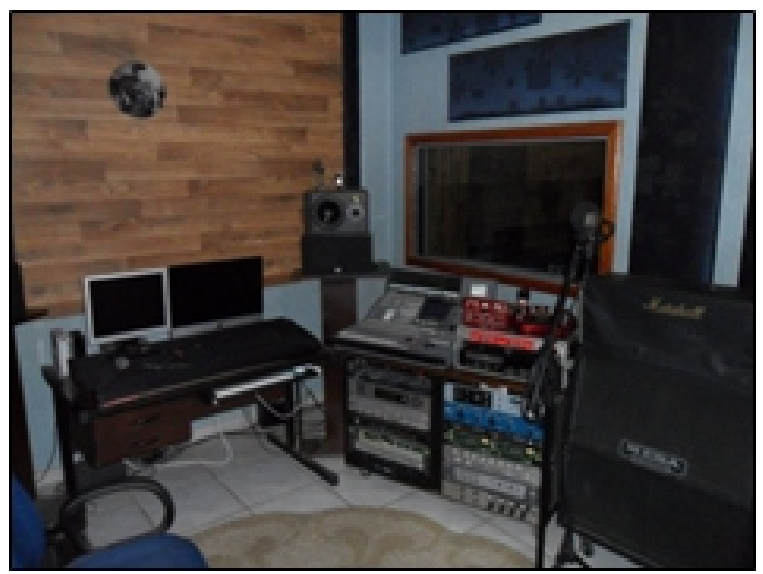

Figura 5. Equipamentos de gravação musical. São Paulo, novembro de 2011. Autor: Villy Creuz

Em certo sentido, podemos afirmar que se amplia a divisão do trabalho no circuito superior marginal emergente, com novas especializações e repartições do trabalho. Implica, igualmente, o aumento da densidade comunicacional entre os atores, pois a interdependência de funções é necessária para alcançar o produto final. Por essa razão, a telefonia móvel, fixa e por rádio tem sido largamente utilizada entre esses agentes, bem como o intercâmbio de mensagens de texto, via sms (torpedos) e e-mails. 0 "boca a boca" é potencializado frente à densidade de comunicação entre esses agentes.

0 aumento da divisão do trabalho na produção de música, com terceirização dos serviços, alarga-se. Pequenas gravadoras, como em Goiânia, passaram a focar seus serviços na pré-produção.

A pré-produção trabalha com os arranjos musicais, o repertório e, em seguida, escolhem-se as empresas que irão executar os serviços como gravação, mixagem, masterização, parte gráfica (encartes) e, por fim, a prensagem do disco. Em geral, o valor cobrado pela gravadora ao artista é de, em média, $\mathrm{R} \$ 30.000,00$. 0 custo é cobrado ao artista e a empresa repassa às demais firmas os pagamentos pelos demais serviços.

Como exemplo, tomemos uma empresa familiar, em Goiânia, na qual trabalham o pai (fundador e pastor evangélico) e a filha, esta última é quem organiza a repartição de funções na firma. 0 argumento sustentado pelos proprietários é de que já não é interessante investir em equipamentos, já que o custo é alto e haveria a necessidade de manter funcionários para operá-los. Por isso, escolheram comandar as etapas do trabalho a partir da terceirização de serviços. A margem média de lucro da empresa é de $60 \%$ a $70 \%$.

Uma manifestação que nos parece interessante ressaltar é o aumento de empresas com maior inclinação a atender públicos específicos. Isto é, empresas focadas em produções de roqueiros, evangélicos, duplas sertanejas, forrozeiros, sambistas e assim por diante. Públicos que se relacionam aos gêneros.

Na dinâmica das atividades ligadas à produção musical é corrente haver parcerias com músicos e empresas de gravação e casas de show. Por essa razão, serviços especializados também encontram um mercado, sobretudo com o aumento de demanda por serviços musicais nas metrópoles.

As cidades acolhem satisfatoriamente esses conjuntos de empresas em razão da configuração territorial, abrigando o trabalho morto, mais o trabalho vivo. Esses trabalhos acumulados, suas formas (trabalho morto), permitem o exercício de atividades que, noutra configuração, teria outro arranjo organizacional.

A configuração espacial das cidades é produto da combinação material e imaterial, unidos, conferindo assim especificidades locais. 0 meio construído urbano é expressão dessa dinâmica, muito embora também seja a condição de realização. "A cidade - sobretudo a grande cidade - constitui um meio material e um meio social adequados a uma maior socialização das forças produtivas e de consumo" (Santos, 1994, p. 120).

Os capitais comuns são, através dos meios coletivos colocados à disposição do processo de produção nas cidades, formas geográficas de realização do trabalho vivo sobre o trabalho morto. 0 meio construído opera como essa mediação de recursos postos ao uso comum.

A noção de socialização capitalista, de Christian Topalov (1974), define que a cidade é o resultado da divisão social do trabalho, sendo a cidade a própria economia, como propunha Roger Lee.

Milton Santos (1994, p.122), ao tratar sobre a socialização capitalista, pondera:

Entenda-se por socialização capitalista a criação de capitais comuns, de meios coletivos à disposição do processo produtivo. É socialização pelo fato de que não são os capitais individuais que a devem empreender diretamente; é capitalista porque os beneficiários são poucos, segundo uma hierarquia que vêm do seu poder enquanto capitalista, isto é, de sua capacidade de utilizar produtiva e especulativamente as 
infra-estruturas financiadas por meio de impostos, com o esforço coletivo, isto é, mediante a contribuição social. A socialização capitalista é, sobretudo, um processo de transferência de recursos da população como um todo para algumas pessoas e firmas.

A economia política das cidades pressupõe o entendimento da distribuição de tarefas, funções e formas nos lugares. De modo que o meio construído urbano é central à compreensão do fenômeno dos dois circuitos da economia, nos quais a coexistência de atores com enormes disparidades de poder, influência, organização, capital e tecnologia são consonantes. Os agentes sociais mais fracos resistem nos interstícios que as possibilidades técnicas ampliam no atual período.

\subsection{Comercialização e Distribuição de músicas}

Os trabalhos de campo em São Paulo, Rio de Janeiro, Porto Alegre, Recife e Goiânia, revelaram muitos exemplos de uma dinâmica economia urbana produzida por atores não poderosos. Novas formas de produzir e consumir estão presentes no período. Exemplos em que indivíduos encontram formas inovadoras de trabalhar, com pouco dinheiro e com necessidade de gerar renda, aumentam as possibilidades de trabalho.

0 primeiro exemplo é um senhor boliviano, entrevistado em Goiânia, que grava músicas em sua casa, com seu instrumento de sopro para fabricar discos em seu próprio estúdio que é formado de um computador, uma mesa de som, uma impressora, cabos e microfones.



Figura 6. Goiânia. Comercialização de Discos no Setor Central, 2010. Autor: Villy Creuz
Os CDs são vendidos no setor central da cidade pelo preço de $\mathrm{R} \$ 10,00$. 0 lucro dessa atividade destina-se ao consumo familiar e à compra de insumos de acordo com a demanda. A figura abaixo ilustra como se realiza a comercialização.

0 aparelho de reprodução de discos é ligado na caixa de som para que os possíveis clientes ouçam. Não há propaganda, nem folhetos, nem cartões.

Há outro tipo de comercialização: CDs virgens são gravados com temas musicais - como músicas românticas, para festas, etc. - e gêneros - sertanejo, forró, rock, eletrônicas, etc. Geralmente esses discos, com um grande conjunto de músicas (aproximadamente 300 em formato MP3 ${ }^{4}$ ), são vendidos a R\$ 5,00 nas centralidades de São Paulo, Rio de Janeiro, Porto Alegre e Goiânia. A figura abaixo ilustra a compra e a venda de discos nessas situações.

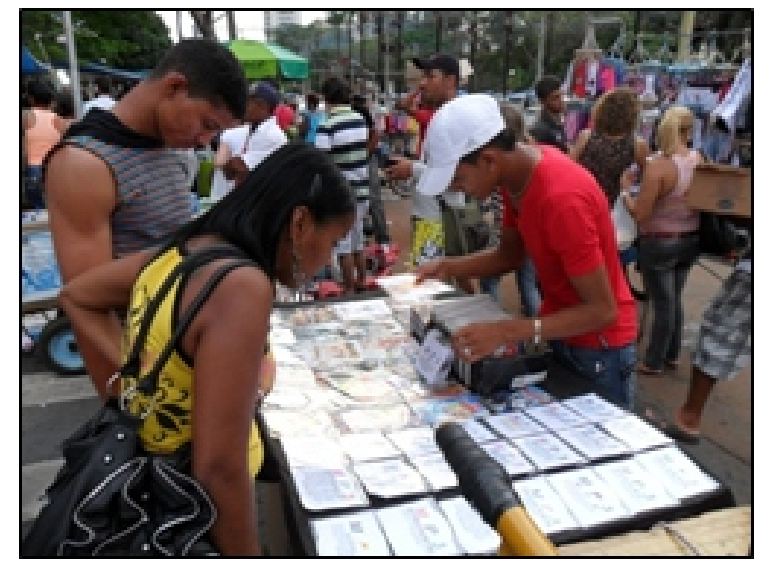

Figura 7. Comercialização de CDs de MP3. Goiânia, novembro de 2010. Autor: Villy Creuz

Em Olinda, região metropolitana de Recife, encontramos mais um caso de comercialização nas ruas da cidade, em que o comerciante negociava discos de MP3 a R\$2,00. Havia uma sazonalidade na procura pelos gêneros, já que, a exemplo das festas de São João, típicas do estado de Pernambuco, a procura por forró tende a ser maior. Já no carnaval aumenta a procura por discos de frevo.

Esse mecanismo de comercialização na imagem acima possui um pequeno sistema técnico, permitindo ao potencial cliente testar a qualidade do disco antes da aquisição. A mobilidade é outra vantagem, pois, em geral o deslocamento é constante durante o dia de trabalho (variando de 8 a 12 horas por dia), em direção aos nós de circulação na cidade ou, ainda, na tentativa de escapar da fiscalização municipal.

${ }^{4}$ MP3 é uma abreviação de MPEG 1 Layer 3 ou Mini Player-camada 3. É uma forma de comprimir arquivos sonoros de modo que a a audição não perceba claramente o encolhimento de camadas sonoras. 


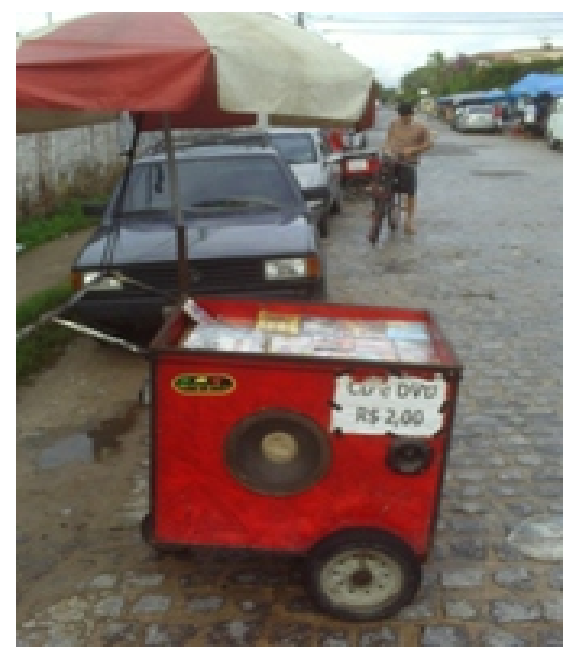

Figura 8. Carrinho de discos e DVDs, Olinda-PE, junho de 2011. Autor: Villy Creuz

Mais um exemplo desse tipo de comércio é o desenvolvido pelo pastor evangélico que vende seus discos todos os finais de semana na feira da Praça do Pôr-do-Sol que acontece aos sábados, no setor oeste da cidade de Goiânia. 0 disco custa R\$ 10,00 .

De posse apenas de uma pequena bolsa e um reprodutor de CD para que os clientes possam escutar seu som, o pastor evangélico comercializa o disco que gravou com a família, na qual o pai é o baixista, a filha é a vocalista, o caçula é o baterista e o primogênito toca com a guitarra. Os três discos eram produzidos por ele e sua família com conteúdos religiosos. Veja a foto que ilustra a situação.

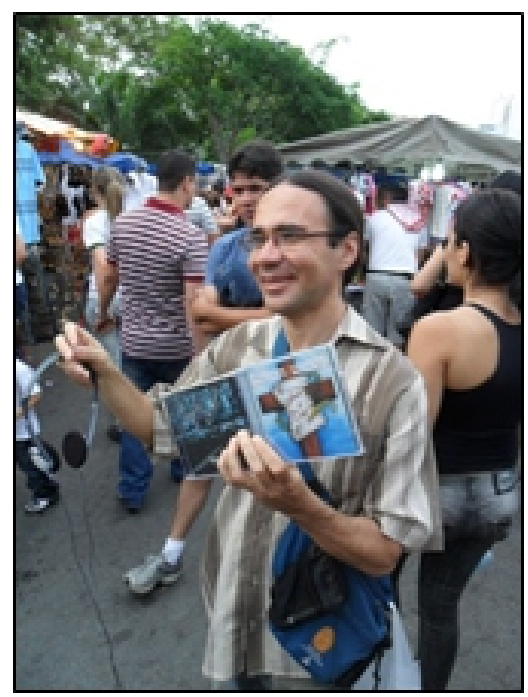

Figura 9. Goiânia. Comercialização de Discos no Setor Oeste, 2010. Autor: Villy Creuz

Mais uma forma de comercialização de discos é a venda em bancas de jornal na região central da cidade de Goiânia. Como se podem observar nas próximas duas imagens há uma exposição dos CDs comercializados e uma procura por esse tipo de presteza. Os discos são vendidos pelo valor de $\mathrm{R} \$ 9,90$. Neste local eram comercializados diversos outros tipos de artigos, como livros, cartões de recarga para telefonia celular, jornais, mapas das cidades, doces, entre outros. Esse é um exemplo de associação de produtos, de que nos fala Montenegro (2006).

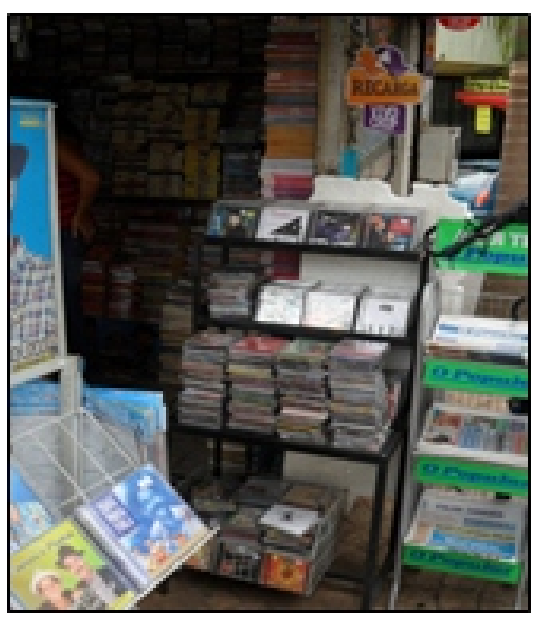

Figura 10. Goiânia. Venda de Discos no Setor Central, 2010. Autor: Villy Creuz

Ao questionar sobre a origem dos CDs de cantores conhecidos, como Chitãozinho e Xororó, Leandro e Leonardo, Sergio Reis, entre outros, o entrevistado limitou-se a responder: "Um rapaz me traz". Com relação aos outros artistas, afirmou ser comum que duplas sertanejas deixem seus discos em consignação na banca, junto com a propaganda dos shows.

Percebe-se, em geral, que a organização dessas atividades é pouco complexa, na qual o peso das relações pessoais, o contato direto com clientes e revendedores na obtenção de produtos está relacionado com a troca de informações pessoais.

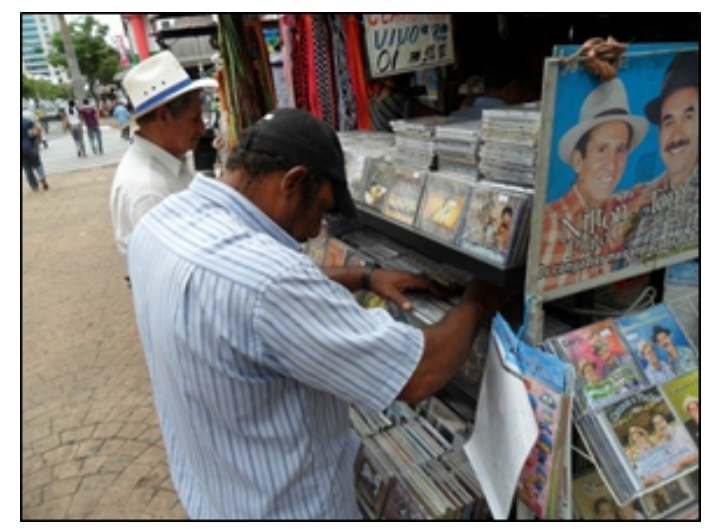

Figura 11. Goiânia. Consumo de Discos no Setor Central, 2010. Autor: Villy Creuz 
É corrente na paisagem urbana dessas cidades encontrarmos situações semelhantes da imagem na sequência, em que um sujeito, em uma superfície de papel grosso, exponha os discos que oferece para vender. Normalmente, esses vendedores possuem equipamentos portáteis para reproduzir a mercadoria. 0 produto desse material, segundo algumas entrevistas, é oriundo da Internet, via sítios para baixar arquivos musicais.

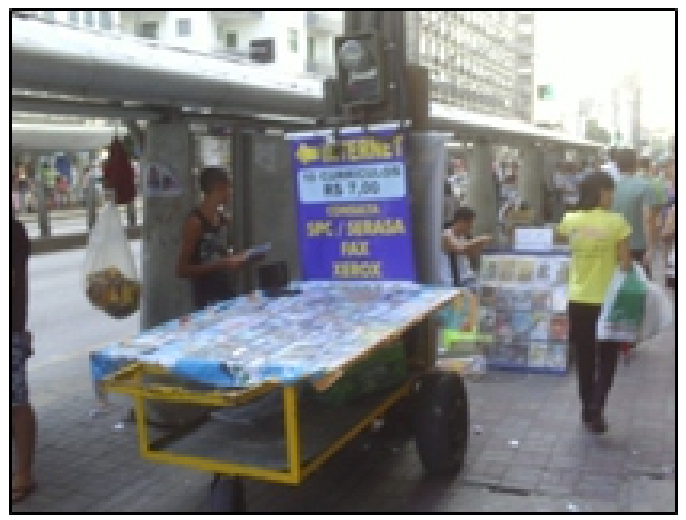

Figura 12. Comércio do Circuito Inferior de Discos, Recife-PE, junho de 2011

Nessa imagem, em uma avenida no centro de Recife, nota-se o aparelho no carrinho, com a finalidade de fazer os testes nos DVDs e CDs. Junto aos produtos, uma faixa indicando o local para confecção de currículos e, do mesmo modo, a possibilidade de consulta ao Serasa ${ }^{5}$ e ao SPC $^{6}$.

A imagem evidencia três coisas: a primeira, a busca pelo som e pela imagem, produtos da indústria cultural perpassam todos os segmentos sociais. Há deveras uma psicoesfera mediada pela indústria da música e indústria cinematográfica, criando um discurso sobre o mundo. Os filmes piratas, vendidos na banca sobre o papelão, são os mesmos que passaram nas grandes redes de cinema e que depois serão veiculados pelas companhias de televisão.

A segunda, a regulação por meio do crédito impõe a normatização. A existência do Comprovante de Situação Cadastral (CPF), particular ao Brasil, é uma maneira de regulação na qual há os registros pelas situações dos compromissos financeiros das pessoas físicas. Apenas desse modo é que se pode obter crédito para consumo. A norma e a técnica são articuladas de tal modo que a eficiência da primeira apenas pode decorrer da existência da segunda - método de controle online dos registros. O CPF é, no país, cada vez mais notório.
Por fim, a terceira evidência da imagem anterior é a necessidade por trabalho, tanto pela demanda de empregadores, quanto para a oferta de empregados, figurados aí, nessa imagem, no imperativo da organização dos currículos.

Provavelmente, quem demanda por esse tipo de serviço (organização de currículos) não tenha equipamento para fazê-lo ou não domine o savoir-faire das tecnologias informáticas. De um jeito ou de outro, é uma normatização exigida e corrente para todos os postos de trabalho, desde equipes de limpeza até diretores de companhias. É um novo tipo de serviço nas centralidades urbanas, associados, algumas das vezes, ao comércio de discos.

Também em Recife, no centro velho, encontramos outro tipo de comercialização da imagem abaixo, no qual o proprietário é o único a trabalhar, com a diversificação do negócio, transformando as mídias antigas, como fitas magnéticas e discos de vinil em Cds.

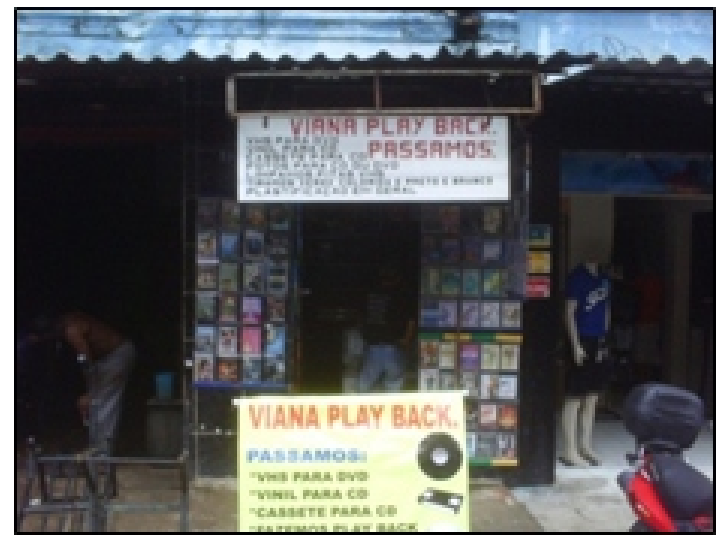

Figura 13. Comércio de discos no Circuito Inferior, Recife, junho de 2011. Autor: Villy Creuz

Nesse estabelecimento, da figura anterior, trabalha-se com o sistema bancário, ao aceitar cartões de crédito e débito em suas transações. 0 aluguel era considerado baixo pelo entrevistado, em torno de $\mathrm{R} \$ 500,00$. A variedade de funções ajudava o proprietário a angariar mais clientes, como cópias de CDs, venda de discos virgens, cópias em impressão colorida e preto e branca. A localização era decisiva para a empresa (sem registro), pois o volume de transeuntes potencializa o negócio.

0 meio construído urbano é, também, o lugar da socialização de trocas sensoriais. Torna-se corrente nas cidades encontrar propagandas de grupos sobre suas apresentações. Evidencia-se, do

${ }^{5}$ Empresa de consulta de crédito. Serasa Experian.

${ }^{6}$ SPC Brasil é o sistema de informações das Câmaras de Dirigentes Lojistas, com o maior banco de dados da América Latina em informações creditícias sobre pessoas físicas e jurídicas. 
mesmo modo, a interdependência de atividades na divisão social e territorial trabalho dentro das metrópoles brasileiras, com a participação de gráficas no circuito espacial de produção musical, ao fabricarem os encartes e folhetos desses shows.

\section{A porosidade da música no território}

O aumento da repartição de tarefas condiciona à maior participação do consumo entre famílias nos mercados das cidades. Formas de trabalho com aportes tecnológicos transformam a organização espacial das atividades ligadas à música.

Os objetos técnicos, articulados em sistema, tramam uma nova relação dos aconteceres da práxis cotidiana. Nesse raciocínio Silveira (2009, p. 21) afirma que

não é apenas a introdução de novas máquinas, mas sobretudo um novo modo de relação entre processos simbólicos e formas de produção e distribuição dos bens e serviços. Um novo modo de produzir indissociavelmente ligado a um modo de comunicar.

As micro, pequenas e médias atividades ligadas à música, apesar de sua subordinação aos grandes e a influência na deformação do perfil da demanda, encontram também lugar para sua reprodução, por vezes genuína e espontânea, por vezes vítimas do mimetismo que lhes garante o retorno financeiro.

Ao falar de micro e pequenos estúdios de gravações musicais e pequenas gravadoras, portadoras de técnicas modernas, mas com grau de organização e capital reduzidos, que encontram no meio construído urbano a possibilidade da manutenção de suas atividades, com o pagamento de aluguéis mais baratos e com uso misto de moradia e local de trabalho, constituem-se novas formas espaciais de geração de renda entre diferentes camadas da população.

Onde quer que estejamos, a música, a melodia e a sonoridade estão presentes. Onde o homem está, haverá produção de trabalho por meio da cultura e da música. As grandes metrópoles são o berço dessa produção cada vez mais ampliada.

Por essa razão, atividades ligadas à música percebem seus mercados aquecidos como constatado em São Paulo, Goiânia, Recife, Porto Alegre e Rio de Janeiro, com o surgimento de estúdios caseiros, micros, pequenos e médios estúdios de gravação e gravadoras, bem como as organizações relacionadas ao comércio musical - lojas de discos, ambulantes e lojas de instrumentos e consertos.
Esse conjunto de atividades é possível em decorrência da flexibilização das técnicas e do arranjo no meio construído urbano de atores com vontade de trabalhar com a música. A atividade musical movimenta a economia política das cidades e o território é preenchido por manifestações culturais sobre o sentido do uso do espaço geográfico; e, por essa dinâmica, criam-se novas firmas e se gera renda a um considerável conjunto de atores sociais.

\section{Referências}

BARBERO, J. M. Dos meios às mediações: comunicação, cultura e hegemonia. Trad: Ronald Polido e Sérgio Alcides. 6a ed. Rio de Janeiro, Editora UFRJ, 2009.

BARENBOIM, D. A Música desperta o tempo. Martins Fontes, São Paulo, 2009.

BAUDRILLARD, J. O sistema dos objetos. Editora Perspectiva, São Paulo. [1968] 1973.

BULL, M. Sounding out the city: personal stereos and the management of everyday life. Oxford. New York, 2000.

GOLDMANN. L. A Criação Cultural na Sociedade Moderna. Difusão Européia do Livro, São Paulo, 1972.

LIPOVESTKY, G. A Era do Vazio. Tradução: Therezinha Monteiro Deustch. Manole. Barueri, [2005] 2009.

MAFFESOLI, M. A República dos Bons Sentimentos. Iluminas: São Paulo, 2008.

MERLEAU-PONTY, M. Elogio da Filosofia. Tradução: António Braz Teixeira. 5.ed. Lisboa, 1998.

O Olho e o espírito. Coleção Os Pensadores, v.41, 1975, Abril S.A., Cultural e Industrial, São Paulo.

Linguagem e Fenomenologia. Coleção Os Pensadores, v.41, 1975, Abril S.A., Cultural e Industrial, São Paulo.

MUMFORD. L. Arte e Técnica. Martins Fontes. São Paulo, 1952.

MONTENEGRO, M. R. O circuito inferior da economia urbana na cidade de São Paulo. Dissertação de 
Mestrado, Departamento de Geografia, Universidade de São Paulo, 2006.

ORTEGA Y GASSET, J. Meditação da Técnica. Rio de Janeiro: Livro Ibero Americano, Lisboa [1939] 1963.

SANTOS, M. O Espaço Dividido - os dois circuitos da economia urbana dos países subdesenvolvidos. São Paulo: Edusp, [1979] 2004.

, M. "Metrópole: a força dos fracos é seu tempo lento". Ciência \& Ambiente, IV (7), jul/dez, 1993.

M. Por uma economia política da cidade -o caso de São Paulo. Hucitec-Educ, São Paulo, 1994.

M. Técnica, Espaço, Tempo: globalização e meio técnico-científico informacional. 4. Ed. Editora Hucitec. São Paulo, [1994] 1998.

M. A Natureza do Espaço - técnica e tempo razão e emoção. São Paulo: Hucitec, 1996.
SILVEIRA, M. L. "Uma situação geográfica: do método à metodologia". In: Território, ano IV, n 6, jan/jun. São Paulo, 1999.

M. L. "Indagando as técnicas: um caminho para entender o território". In: Os lugares do mundo - globalização dos lugares, Gonçalves, N. M. S.; Silva, M. A.; Lage, C. S. (Org.), Universidade Federal da Bahia, Salvador, BA, 2000.

M. L. "Ao Território Usado a Palavra: pensando princípios de solidariedade socioespacial". In: d'Avila Viana, A. L.; Ibañez, N.; Elias, P. E. (Org.) Saúde Desenvolvimento e Território, 2009, p.127150.

M. L. Urbanización Latino Americana y Circuitos de la Economía Urbana. In: Revista Geográfica de América Central, $\mathrm{n}$ - especial. II semestre de 2011, Costa Rica, 2011.

SIMONDON, G. El modo de existencia de los objetos técnicos. Buenos Aires: Prometeo Livros, 2007.

\title{
Music and Jobs in the cities: the marginal upper and lower circuit in São Paulo, Rio de Janeiro, Porto Alegre, Recife, and Goiania
}

\begin{abstract}
Since the 1990s, the number of companies involved in the production, distribution and consumption of music has been rearranged due to the installation of new geographical forms in the national territory. New technical systems have transformed the factors of production and the social and territorial division of labor between these agents. Concomitantly with the arrival of these new families of techniques, there is, likewise, the banalisation of work equipment, mainly the ones connected with sound digitization. The modernization of the country, which ran faster in the last two decades, has increased the division of tasks between social actors involved with music. Through some concrete situations in fieldwork in cities like São Paulo (SP), Rio de Janeiro (RJ), Goiânia (GO), Porto Alegre (RS) and Recife (PE), this work will try to demonstrate the coexistence between these social actors, specially focusing on recording and musical rehearsal studios and micro and small record labels.

Keywords: Music Production. Cities and Technique.
\end{abstract}

\section{Musica y Trabajo en las ciudades: el circuito superior marginal e inferior en São Paulo, Rio de Janeiro, Porto Alegre, Goiânia y Recife}

\begin{abstract}
Resumen - Desde de década de 1990 el conjunto de empresas musicales vive la reorganización de actividades de producción, distribución y consumo. Debido a la instalación de fijos geográficos en el territorio, ese movimiento gana fuerza. La disposición de un nuevo sistema de técnicas ha cambiado la división social y territorial del trabajo entre esos actores. Junto con la llegada de esas nuevas herramientas hubo la banalización de esas tecnologías, fundamentalmente las que corresponden a la digitalización musical o a los insumos de la informática. Por medio de situaciones concretas en los trabajos de campo en las ciudades de São Paulo (SP), Río de Janeiro (RJ), Goiânia (GO), Porto Alegre (RS) y Recife (PE), trataremos demostrar la coexistencia entre actores sociales, en especial, los estudios de grabación musical y micro y pequeñas grabadoras.
\end{abstract}

Palabras clave: Ciudades. Técnica y Producción Musical. 